\title{
Utilization patterns of complementary and alternative medicine in Australia, Canada and the United States: popularity of dietary supplements, mind- body and manipulative therapies
}

\author{
Marina Luketina Sunjka ${ }^{1}$, Ana Pejcic ${ }^{1}$, Mihajlo Jakovljevic ${ }^{2}$ \\ Faculty of Medical Sciences, University of Kragujevac, Kragujevac, Serbia \\ Global Health, Economics and Policy, Faculty of Medical Sciences, University of Kragujevac, Kragujevac, Serbia
}

\begin{abstract}
INTRODUCTION
Complementary and alternative medicine (CAM) includes diverse modalities and products that are not integral part of conventional, mainstream medicine [1]. During the past decade, the interest in CAM has increased and the attitude of the general population towards CAM appears to be generally positive [2-3]. It is evident that expenditure on CAM varies worldwide, but it is difficult to put a precise figure on the global expenditure on all CAM approaches due to inconsistency in terminology and regulatory status in different countries [4]. Recent surveys have estimated that substantial amount of money is spent out-of-pocket on CAM. In the USA annual estimates varied from USD 30.2 billion to USD 34.4 billion during a 1997-2012 period [5-9], with annual estimates representing about $11.9 \%$ and $9.2 \%$ of all out-of-pocket spending on health care and $1.5 \%$ and $1.1 \%$ of total health care spending in 2007 and 2012, respectively $[6,8,10]$. In Canada estimates of annual out-of-pocket expenditure on CAM were CAD 3.8 billion in 1997 [11] and CAD 7.8 billion in 2006 [12]. In Australia, in the period 1993-2004, the estimated annual out-of-pocket expenditure on CAM varied from AUD 930 million to AUD 2,287 million [13-15].
\end{abstract}

\section{PATTERNS OF USE OF CAM IN AUSTRALIA, CANADA AND THE UNITED STATES}

If we observe results of the follow-up nationally representative surveys in Australia [13-
15], Canada [11,12] and the United States (random household telephone surveys $[5,16]$ and National Health Interview Surveys [69,17-18]) (Table I) we can easily notice that usually the same types of CAM were among the top 5 most frequently used therapies in the past 12 months, just the order is slightly different across some of the observed years. Although the approaches included in the supplement of National Health Interview Surveys related to the CAM use in the USA mostly remained constant, there were still slight variations among survey years which preclude direct comparison of the results for questions that were not asked consistently each time [9]. There were also differences in categorization of CAM compared to earlier studies that were conducted as random household telephone surveys $[5,16]$. Despite this, we can notice that most popular domain during 1990 [16], 1997 [5], 1999 [17] and 2002 [18] were mind-body therapies. On the other hand, in 2007 [6,7] and 2012 [8,9] surveys showed that non-vitamin non-mineral dietary supplements were the most commonly used complementary approach. However, it seems that percentage of non-vitamin non-mineral dietary supplements use didn't change substantially over years - in 2002 18.9\% respondents reported using them during past 12 months [18], and in 2007 [6,7] and 2012 [8,9] the observed percentage remained constant $(17.7 \%)$. In addition, in 2002 CAM was defined more broadly by including prayer specifically for health purposes as CAM practice leading to estimated prevalence of CAM use of $62 \%$, but when this type of CAM was
Corresponding author Ana Pejcic anapejcic201502@yahoo.com

\section{Disclosure}

$\mathrm{MJ}$ is a Board Member of the journal Farmeconomia. Health Economics and

Therapeutic Pathways. AP is awarded with the Scholarship of the Ministry of Education, Science and Technological Development of the Republic of Serbia for PhD students. Publication of results was not contingent to Ministry's censorship or approval. 
excluded $36 \%$ of adults have used some type of CAM during previous 12 months [18]. In the surveys in the subsequent years $(2007$ and 2012) prayer specifically for health purposes was not considered to be CAM approach [69] and the reported prevalence of CAM use was $38.3 \%$ in 2007 [6,7] and $33.2 \%$ in 2012 [9-10]. Taking this example into account, it should be emphasized that direct comparison of the prevalence and expenditures across studies may be misleading without taking into consideration which health approaches are included in the definition of CAM [9]. Use of CAM in the USA was more prevalent among women, middle-aged group, with higher level of education and who were not poor [5$7,16,17]$. People who take natural products (dietary supplements other than vitamins and minerals) or practice yoga were more likely to do so for wellness reasons than for treating a specific health condition [10]. On the other hand, people who use manipulative techniques more often do so for treatment reasons rather than wellness [10].

Mind-body and manipulative therapies were dominant forms of CAM in Canada in 1996 and 2007 [11,12]. The use of CAM was more prevalent in 18-34-year-old age group and those with higher level of education $[11,12]$. The majority of respondents used CAM for wellness, in order to prevent future illness from occurring or to maintain health and vitality $[11,12]$.

In Australia, based on data collected via the South Australian Health Omnibus Survey, manipulative therapies and self-prescribed vitamins consistently were the most commonly used type of CAM in Australia from 1993 to 2004 [13-15]. CAM was mostly used to maintain general health and greatest use of CAM was noted among women aged 25-34 years with higher income and education levels who live in metropolitan area and were born in Australia [13-15].

\section{Dietary supplements}

Non-vitamin, non-mineral, dietary supplements remain popular and frequently used despite unclear health benefits [9]. In the USA in 2002 the most commonly used nonvitamin, non-mineral, natural products were Echinacea, ginseng, Ginkgo biloba and garlic supplements [18]. The situation was changed in 2007 and 2012 in favor of fish oil supplements and glucosamine, chondroitin or combination supplements [7,9]. In 2007 and 2012 in the USA public spent USD 14.8 billion and USD 12.8 billion out-of-pocket on the purchase of natural product supplements, which was approximately $31 \%$ and $24 \%$ of the amount paid out-of-pocket for prescription drugs in 2007 and 2012 (USD 47.6 billion and USD 54.1 billion), respectively [6,8].

Herbal therapies were ranked fifth in Canada in both 1997 and 2006 and mostly used for treatment of colds/flu [11,12]. High dose/ mega vitamins were not so popular in Canada and $3 \%$ and $2 \%$ of respondents have used it in 1997 and 2006, respectively [11,12]. Insurance coverage was below $12 \%$ for respondents using high dose/mega vitamins and herbal therapies, whereas projected national expenditure on herbs and vitamins was about CAD 937 million in 1997 and CAD 923 million in 2006 [11,12].

In Australia self-prescribed vitamins were the most used products from 1993 to 2004 [13-15], followed by herbal medicines in 1993 and 2004 [13,15]. In 1992/1993 estimated amount spent on CAM products has almost doubled the amount of patient contributions for all pharmaceutical drugs purchased in Australia [13]. In 2000 people paid almost four times more for alternative therapies than contributions to all pharmaceuticals [14]. In 2004 the overall extrapolated expenditure on CAM products decreased from AUD 1.67 billion in 2000 to AUD 1.31 billion in 2004, probably due to the decrease in number of products used per person following adverse publicity in the media surrounding CAM products in 2003 during the Pan Pharmaceutical crisis when concerns were raised about the content and quality control of products made by this manufacturer [15].

\section{Mind-body therapies}

Mind-body therapies include a wide range of practices designed to facilitate the capacity of the mind to affect health [19]. As they usually involve inexpensive self-care based activities, they seem to be a cost-saving alternative in an age of increasing medical expenditures $[19,20]$.

The mind-body practices most commonly used by adults in the USA include yoga, deep-breathing exercises and meditation $[9,10]$. The percentage of adults who practice yoga has increased substantially, from $5.1 \%$ in 2002 to $6.1 \%$ in 2007 and $9.5 \%$ in $2012[9,10]$. Since yoga is offered in a variety of settings ranging from self-practice to specialized studios, it is not unexpected that the yoga industry experienced such growth in recent years [9]. In 1999 and 2002 prayer and spiritual healing were very popular in the USA $[17,18]$.

Prayer and relaxation techniques were the two most popular CAM approaches in 1997 in Canada [11]. However, they became less popular in 2006 [12]. Sizable increase in the use of yoga was also noted - from 4\% in 1997 


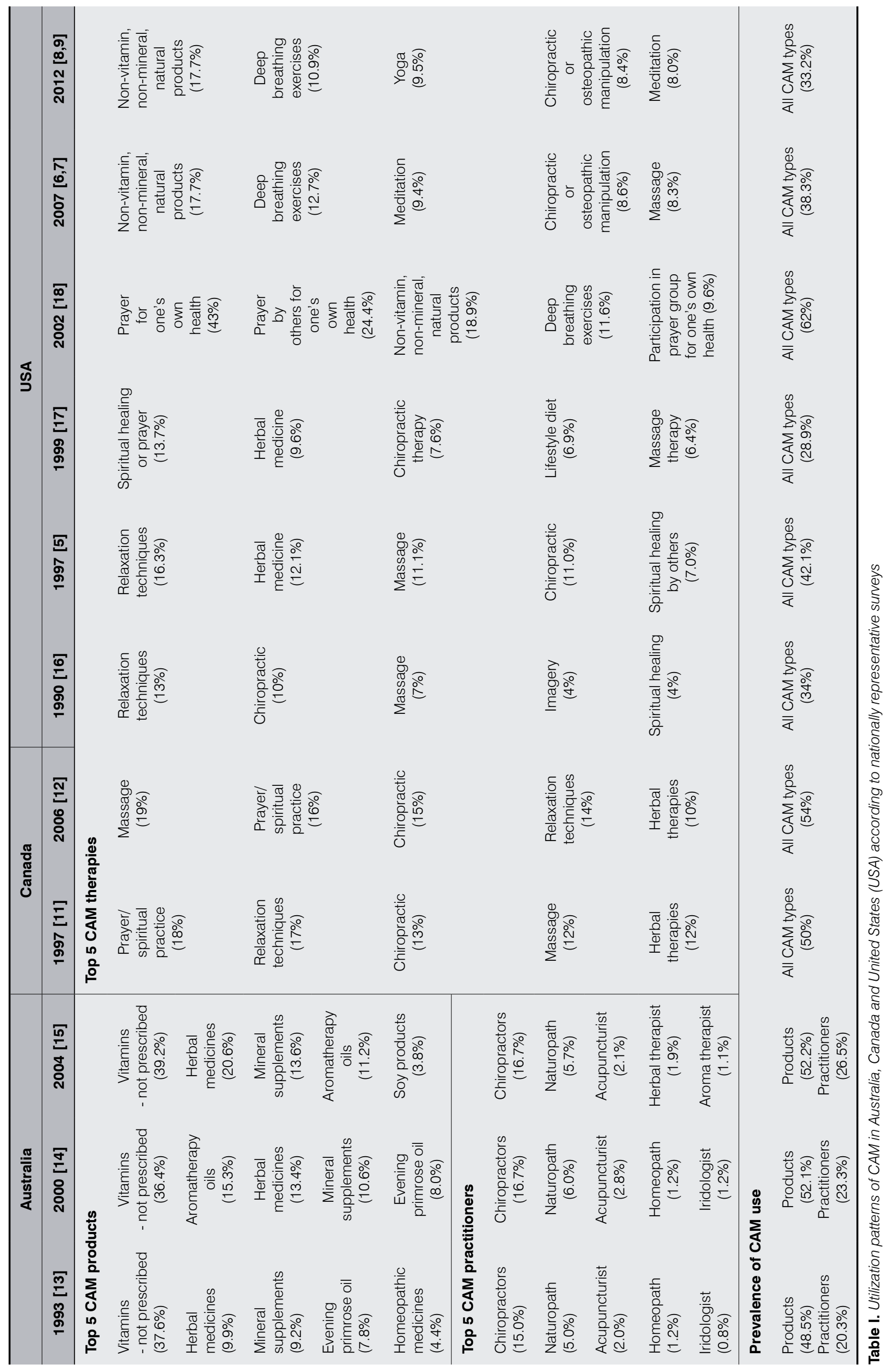


[11] to $9 \%$ in 2006 [12]. Prayer is a therapy typically started at an earlier age: 15 to 19 (with a national average of age 18), and mostly used for general overall health [11,12]. Relaxation techniques were usually first tried between ages 26 and 33 (national average was age 29) and used for the treatment of stress [12]. Insurance coverage for relaxation techniques was $8-9 \%[11,12]$.

Mind-body interventions were not so popular in Australia [13-15]. Aromatherapy oils were the only CAM products from this group of CAM approaches ranked second and fourth in 2000 [14] and 2004 [15], respectively.

\section{Manipulative therapies}

Manipulative therapies, such as chiropractic or osteopathic manipulation and massage, are also considered to be one of the frequently used CAM methods. Chiropractors were the most frequently visited CAM practitioners in Australia in all three surveys [13-15].

In Canada, in both 1997 and 2006, they were ranked third [11,12]. Respondents typically first tried chiropractic care between ages 27 and 34 years [12]. In addition, massage became the most popular CAM method in 2006 [12]. Both massage and chiropractic care were usually used for back or neck problems $[11,12]$. Interestingly, respondents who used chiropractic care reported that about $75 \%$ and $72 \%$ of the cost were covered by health insurance in 1997 and 2006, respectively [11,12]. The costs covered by insurance for massage therapy rose 21 percentage points - from $36 \%$ to $57 \%$ from 1997 to 2006 [11,12].

Chiropractic or osteopathic manipulation in the USA were ranked second in 1990 [16], third in 1999 [17] and fourth in 1997 [5], $2007[6,7]$ and $2012[8,9]$ by prevalence of use. Chiropractic care can also be covered by insurance in the USA, e.g. some states mandate coverage of chiropractic care in private insurance, the US Congress has authorized that some chiropractic services be covered by Medicare and Medicaid, and federal employees have chiropractic coverage in the Federal Employee Health Benefit Program and in the Federal Employee Worker's Com- pensation Program [21,22]. In 2012, partial insurance coverage was more common than complete coverage for chiropractic care and massage [10].

\section{CONCLUSIONS}

The magnitude of the demand for CAM is noteworthy in Australia, Canada, and the USA. Some differences in patterns of use can be observed in previously described national surveys in these countries, but they should be interpreted cautiously as there were differences in categorization of CAM approaches among them. Broadly regarded, Australians prefer dietary supplements and manipulative therapies. Mind-body and manipulative therapies are preferred among Canadians, whereas people in the USA lean towards the use of dietary supplements and mind-body therapies. These differences could be attributed to many reasons, including cultural, social, economic and technological trends.

Considering observation that people with multiple chronic conditions have an increased likelihood of using CAM, overall aging of the population and increasing prevalence of chronic diseases, it is likely to expect that CAM approaches will become even more popular in the future [12,23-28]. In recognition of the widespread popularity of CAM, leading academic institutions have started to incorporate CAM into medical education, clinical practice and research [29,30]. However, still much remains to be done in this area. There is a growing demand for collecting efficacy and safety data for CAM treatments, as well as reaching consensus regarding uniformity of definition and categorization of various CAM approaches in order to enable comparability of studies conducted in different regions and time periods [31]. Some CAM treatments are covered by insurance in Australia, Canada, and the USA, but more work is needed before CAM becomes more comprehensively included in insurance schemes [32]. A thorough review of economic and health outcomes of CAM treatments is needed for evidence-based consideration of their expenses coverage [33].

\section{REFERENCES}

1. National Center for Complementary and Integrative Health (NCCIH). Complementary, Alternative, or Integrative Health: What's In a Name? Available at: https://nccih.nih.gov/health/integrative-health (last accessed March 2017)

2. Frass M, Strassl RP, Friehs H, et al. Use and acceptance of complementary and alternative medicine among the general population and medical personnel: a systematic review. Ochsner J 2012; 12: 45-56

3. Jakovljevic MB, Djordjevic V, Markovic V, et al. Cross-sectional survey on complementary and alternative medicine awareness among health care professionals and students using CHBQ questionnaire in a Balkan country. Chin $J$ Integr Med 2013; 19: 650-5; https://doi.org/10.1007/s11655-013-1434-6 
4. Pejcic AV, Jakovljevic MB. Economic impact of traditional medicine practice worldwide. Traditional Medicine Research 2017; 2: 60-74; https://doi.org/10.12032/TMR201706039

5. Eisenberg DM, Davis RB, Ettner SL, et al. Trends in alternative medicine use in the United States, 1990-1997: results of a follow-up national survey. JAMA 1998; 280: 1569-75

6. Nahin RL, Barnes PM, Stussman BJ, et al. Costs of complementary and alternative medicine (CAM) and frequency of visits to CAM practitioners: United States, 2007. Natl Health Stat Report 2009; 18: 1-14

7. Barnes PM, Bloom B, Nahin RL. Complementary and alternative medicine use among adults and children: United States, 2007 Natl Health Stat Report 2008; 12: 1-23

8. Nahin RL, Barnes PM, Stussman BJ. Expenditures on Complementary Health Approaches: United States, 2012. Natl Health Stat Report 2016; 95: 1-11

9. Clarke TC, Black LI, Stussman BJ, et al. Trends in the Use of Complementary Health Approaches Among Adults: United States, 2002-2012. Natl Health Stat Report 2015; 79: 1-16

10. National Center for Complementary and Integrative Health (NCCIH). Use of Complementary Health Approaches in the U.S. National Health Interview Survey (NHIS). Available at: https://nccih.nih.gov/research/statistics/NHIS/2012/ key-findings (last accessed March 2017)

11. Ramsay S, Walker M, Alexander J. Alternative Medicine in Canada: Use and Public Attitudes. Vancouver: The Fraser Institute, 1999. Available at: https://www.fraserinstitute.org/sites/default/files/AlternativeMedicineinCanada1999. pdf (last accessed March 2017)

12. Esmail N. Complementary and Alternative Medicine in Canada: Trends in Use and Public Attitudes, 1997-2006. Vancouver: The Fraser Institute, 2007. Available at: https://www.fraserinstitute.org/sites/default/files/ComplementaryAlternativeMedicine.pdf (last accessed March 2017)

13. MacLennan AH, Wilson DH, Taylor AW. Prevalence and cost of alternative medicine in Australia. Lancet 1996; 347: 569-73

14. MacLennan AH, Wilson DH, Taylor AW. The escalating cost and prevalence of alternative medicine. Prev Med 2002; 35: 166-73

15. MacLennan AH, Myers SP, Taylor AW. The continuing use of complementary and alternative medicine in South Australia: costs and beliefs in 2004. Med J Aust 2006; 184: 27-31

16. Eisenberg DM, Kessler RC, Foster C, et al. Unconventional medicine in the United States. Prevalence, costs, and patterns of use. N Engl J Med 1993; 328: 246-52

17. Ni H, Simile C, Hardy AM. Utilization of complementary and alternative medicine by United States adults: results from the 1999 national health interview survey. Med Care 2002; 40: 353-8

18. Barnes PM, Powell-Griner E, McFann K, et al. Complementary and alternative medicine use among adults: United States, 2002. Adv Data 2004; 343: 1-19

19. Wolsko PM, Eisenberg DM, Davis RB, et al. Use of Mind-Body Medical Therapies: Results of a National Survey. J Gen Intern Med 2004; 19: 43-50

20. Sobel DS. MSJAMA: mind matters, money matters: the cost-effectiveness of mind/body medicine. JAMA 2000; 284: 1705

21. McFarland B, Bigelow D, Zani B, et al. Complementary and Alternative Medicine Use in Canada and the United States. Am J Public Health 2002; 92: 1616-8

22. American Chiropractic Association (ACA). Insurance Coverage of Chiropractic: Quick Facts. Available at: https:// www.acatoday.org/Patients/Access-Coverage/Insurance-Coverage (last accessed April 2017)

23. Jakovljevic MM. Comparison of historical medical spending patterns among the BRICS and G7. J Med Econ 2016; 19: $70-6$

24. Jakovljevic M. The aging of Europe. The unexplored potential. Farmeconomia. Health economics and therapeutic pathways. 2015; 16: 89-92; https://doi.org/10.7175/fe.v16i4.1220

25. GBD 2015 Disease and Injury Incidence and Prevalence Collaborators. Global, regional, and national incidence, prevalence, and years lived with disability for 310 diseases and injuries, 1990-2015: a systematic analysis for the Global Burden of Disease Study 2015. Lancet 2016; 388: 1545-602; https://doi.org/10.1016/S0140-6736(16)31678-6

26. GBD 2015 Mortality and Causes of Death Collaborators. Global, regional, and national life expectancy, all-cause mortality, and cause-specific mortality for 249 causes of death, 1980-2015: a systematic analysis for the Global Burden of Disease Study 2015. Lancet 2016; 388: 1459-544; https://doi.org/10.1016/S0140-6736(16)31012-1 
27. Global Burden of Disease Cancer Collaboration. Fitzmaurice C, Allen C, Barber RM, et al. Global, Regional, and National Cancer Incidence, Mortality, Years of Life Lost, Years Lived With Disability, and Disability-Adjusted Life-years for 32 Cancer Groups, 1990 to 2015: A Systematic Analysis for the Global Burden of Disease Study. JAMA Oncol 2017; 3: 524-48; https://doi.org/10.1001/jamaoncol.2016.5688

28. Falci L, Shi Z, Greenlee H. Multiple Chronic Conditions and Use of Complementary and Alternative Medicine Among US Adults: Results From the 2012 National Health Interview Survey. Prev Chronic Dis 2016; 13: E61; https://doi.org/10.5888/pcd13.150501

29. Ventola CL. Current Issues Regarding Complementary and Alternative Medicine (CAM) in the United States: Part 1: The Widespread Use of CAM and the Need for Better-Informed Health Care Professionals to Provide Patient Counseling. P T 2010; 35: 461-8

30. Ventola CL. Current Issues Regarding Complementary and Alternative Medicine (CAM) in the United States: Part 3: Policies and Practices Regarding Dietary Supplements In Health Care Facilities. P T 2010; 35: 570-6

31. Ventola CL. Current Issues Regarding Complementary and Alternative Medicine (CAM) in the United States: Part 2: Regulatory and Safety Concerns and Proposed Governmental Policy Changes with Respect to Dietary Supplements. P T 2010; 35: 514-22

32. Spinks J, Hollingsworth B. Are the economics of complementary and alternative medicine different to conventional medicine? Expert Rev Pharmacoecon Outcomes Res 2009; 9: 1-4; https://doi.org/10.1586/14737167.9.1.1

33. Herman PM, Craig BM, Caspi O. Is complementary and alternative medicine (CAM) cost-effective? A systematic review. BMC Complement Altern Med 2005; 5: 11 